\title{
Best Parameter of the Hostel Building Component Maintenance
}

\author{
Yuseni Ab Wahab \\ Faculty of Business Innovation and Accounting \\ Kolej Universiti Islam Melaka (KUIM), Kuala Sg \\ Baru 78200, Masjid Tanah, Melaka
}

\author{
Abd Samad Hasan Basari \\ Centre for Advanced Computing Technology \\ (C-ACT), Faculty of Information and \\ Communication Technology, UTeM, Hang Tuah \\ Jaya, 76100, Durian Tunggal, Melaka
}

\begin{abstract}
In Malaysia University hostel building maintenance, failure of the component to effective became a major contribution to the university losses and high maintenance cost. Therefore, there is a need to have an optimal maintenance strategy such as replacement, repair and inspection. Before any optimal maintenance strategy can be implemented failure distribution and the parameters of the hostel building component need to be identified. The main objective in this paper is to propose a best of parameter failure distribution for Then, Hostel building maintenance management. The Goodness of a Distribution Fit and Maximum Likelihood Estimator (MLE) techniques in identifying the failure distribution and the parameters of hostel building component. The approach proposed can improve maintenance engineers to use failure data as well as in maintenance optimisation analysis. The paper starts by introducing the application of MLE techniques to identify the best failure fit distribution and its parameters. It follows by numerical examples to determine whether the best fit failure distribution and its parameters are applicable to be applied in maintenance optimisation analysis. This is carried out by comparing the proposed approach with a case study.
\end{abstract}

\section{General Terms}

Pattern Recognition Failure Distribution

\section{Keywords}

Maximum Likelihood Estimator, Goodness of a Distribution Fit and Best fit Failure Distribution

\section{INTRODUCTION}

In reliability and maintainability study, the characteristic of the component will go through decreasing, constant and increasing failure rate. Respectively these characteristics can be presented via the failure distribution of the University hostel building component. There are many types of failure distribution used in reliability analysis such as exponential, weibull, normal and gamma distributions. In the application of maintenance optimisation, the failure distribution of the equipment must be specified before any maintenance strategy is carrying out. Wrong identification of failure distribution will affects the cost of maintenance University hostel building. For example, preventive replacement (PR) strategy to be worthwhile only if the failure rate of the component is increase [1]. If the PR strategy is carried out at decreasing or constant failure rate, the replacement and downtime cost will significantly increase by time. The increasing failure rate can be presented by weibull, normal and gamma distributions, whereas exponential distribution shows the constant failure rate.[4] study on the consequences of mis-specifying the form of the failure distribution of inspection significantly increase by time. The increasing failure rate can be presented by weibull, normal and gamma distributions, whereas exponential distribution shows the constant failure rate.[4] study on the consequences of mis-specifying the form of the failure distribution of inspection

\section{MAXIMUM LIKELIHOOD ESTIMATION (MLE)}

Many computer-based methods present a probability plotting alternative to rank regression; an example is the Maximum Likelihood Estimator (MLE). The idea behind maximum likelihood parameter estimation is to determine the parameters that maximize the probability (likelihood) of the sample data fitting that distribution[6,7 ] .Maximum likelihood estimation endeavours to find the most 'likely' values of distribution parameters for a set of data by maximizing the value of what is called the likelihood function. From a statistical point of view, the method of maximum likelihood is considered to be more robust (with some exceptions) and yields estimators with good statistical properties. In other words, MLE methods are versatile and apply to most models and to different types of data (both censored and uncensored)[8].

\section{GOODNESS OF A DISTRIBUTION FIT}

Statistical goodness-of-fit tests should be applied to test the fit to the assumed underlying distributions. There are many statistical tools that can help in deciding whether or not a distribution model is a good choice from a statistical point of view, which are often based on the type of number of data points and other criteria[5-7 ]. The highest likelihood value in case of MLE. Goodness-of-fit tests including $\chi^{2}$ (chisquare).It is also important to ensure that the time axis chosen is relevant to the problem; otherwise misleading results can be generated [7 ].The methods of exploratory data analysis can be applied when appropriate. Statistical software can be used to rank different distributions based on the best mathematical fit depending on which statistical method is chosen. Note that for the MLE data analysis the ranking of the distributions will be different, since a quantitative measure of goodness of fit (combination of weight factors) will depend on the chosen data analysis method [8 ].

\section{ESTIMATION BASED ON THE SUBJECTIVE SURVEY METHOD}

The same questionnaire used for collection snapshot data is also used for collecting failure data. They are devoted for collecting failure data. Table 1 Template of the failure data included in the Survey Form for the Subjective Survey Method 
Table 1 Template of the failure data included in the Survey Form for the Subjective Survey Method

\begin{tabular}{|c|l|l|l|l|l|}
\hline Name & Designation & Department & $\begin{array}{c}\text { Hostel \& } \\
\text { Room N0. }\end{array}$ & $\begin{array}{c}\text { Street \& } \\
\text { Quarters }\end{array}$ & $\begin{array}{c}\text { Available } \\
\text { Time (09.30 }\end{array}$ \\
\hline & & & & & \\
\hline Nature of complaint & & & & & \\
\hline $\begin{array}{c}\text { Contact Number } \\
\text { (0ptional) }\end{array}$ & & & & & \\
\hline
\end{tabular}

At the time which part of the snapshot analysis is presented to the University, the concept of failure data has been explained to the engineers. Following that explanation, the data collection is started. The data collection took about approximately one year from 1

\section{DATA COLLECTION}

It is recognised the importance of the accurate data for maintenance modelling using failure data concept. In this context data were collected at Kolej Universiti Islam Melaka (KUIM) using a methods, subjective survey (SS).For the SS method, a survey form was designed and delivered to the maintenance engineers at Hostel Building. After collecting a sample for the period of approximately one year dated from 1 July 2012 to 31 December 2012, the completed forms were collected back from the maintenance engineers[4]. The application of the objective method requires data, maintenance records of faults detected at inspection which should be sufficient in quantity and quality. The

Subjective Probability (SP) estimation method has an advantage over the SS method, which is the speed, often reducing to an afternoon that which may otherwise require a survey spanning months and years. However, when a data collection survey is necessary to define maintenance problem and identify engineering solutions, which is typical to this case study, recommended estimating the failure distribution parameter using the SS method in addition to the SP method [4-7 ]. This research does not discuss the result and finding using the SP method since the main purpose of this study is to enhance the SS method. In this research the SS method is used in the first stage to estimate the failure rate distribution.

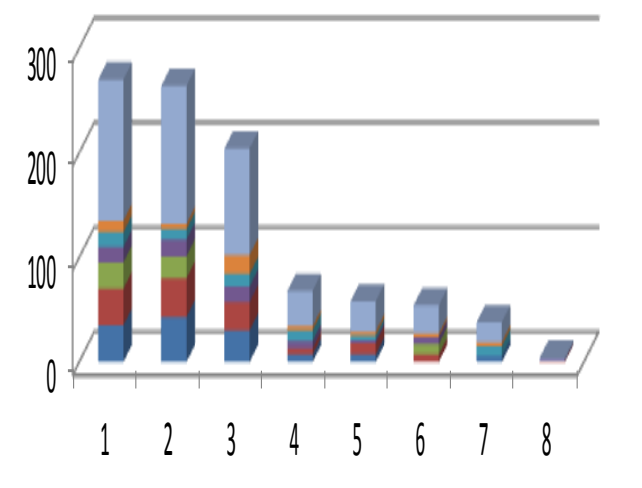

ISeries7

ISeries6

ISeries5

ISeriest

ISeries3

Figure 1: Histogram of the Failure Data
Table 2 shows the questions related to the failure data.

\begin{tabular}{|c|c|c|c|c|c|c|c|c|c|}
\hline & & \multicolumn{6}{|c|}{ CAUSES OF FAULTS OF CIVIL } & \multirow{2}{*}{ 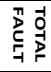 } & \multirow{2}{*}{ 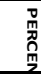 } \\
\hline & & July & August & Sept & Oct & Nov & Dec & & \\
\hline \multicolumn{10}{|c|}{ Total Fault } \\
\hline \multirow{8}{*}{ 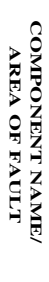 } & Lamp & 35 & 35 & 25 & 15 & 14 & 11 & 135 & 28.1 \\
\hline & Door & 43 & 37 & 21 & 16 & 10 & 5 & 132 & 27.5 \\
\hline & Window & 30 & 27 & & 15 & 12 & 18 & 102 & 21.3 \\
\hline & Shower & 7 & 6 & & 7 & 10 & 4 & 34 & 7.1 \\
\hline & Sink & 7 & 11 & & 3 & 4 & 4 & 29 & 6 \\
\hline & Pipe & & 7 & 10 & 7 & & 3 & 27 & 5.6 \\
\hline & Toilet & 6 & & & & 9 & 4 & 19 & 4 \\
\hline & Bed & & 1 & & 1 & & & 2 & 0.4 \\
\hline & PERCENT & 128 & 124 & 56 & 64 & 59 & 40 & 480 & \\
\hline
\end{tabular}

July 2012 to 31 December 2012. Over the period, about 480 faults were collected. The classification of the high faults obtained is 135 as breakdown with $28.1 \%$ and 2 as detected min faults with $0,4 \%$. This detected fault includes the inspection and corrective actions.

\section{IDENTIFICATION THE BEST FIT FAILURE DISTRIBUTION AND ITS PARAMETERS}

Table 3 : failure Data collection from University Hostel Building

\begin{tabular}{|c|c|c|c|c|c|c|c|c|}
\hline 0.1067 & 0.1067 & 0.1067 & 0.1067 & 0.1067 & 2.16 & 7.3044 & 12.296 & 15.75 \\
\hline 0.1067 & 0.1067 & 0.1067 & 0.1067 & 0.1067 & 2.16 & 7.3044 & 12.296 & 18.03 \\
\hline 0.1067 & 0.1067 & 0.1067 & 0.1067 & 0.1067 & 2.16 & 7.3044 & 12.296 & 18.03 \\
\hline 0.1067 & 0.1067 & 0.1067 & 0.1067 & 0.1067 & 2.16 & 7.3044 & 12.296 & 18.03 \\
\hline 0.1067 & 0.1067 & 0.1067 & 0.1067 & 0.1067 & 2.16 & 7.3044 & 12.296 & 18.03 \\
\hline 0.1067 & 0.1067 & 0.1067 & 0.1067 & 0.1067 & 2.16 & 7.3044 & 12.296 & 18.03 \\
\hline 0.1067 & 0.1067 & 0.1067 & 0.1067 & 0.1067 & 2.16 & 7.3044 & 12.296 & 18.03 \\
\hline 0.1067 & 0.1067 & 0.1067 & 0.1067 & 0.1067 & 2.16 & 7.3044 & 12.296 & 18.03 \\
\hline 0.1067 & 0.1067 & 0.1067 & 0.1067 & 0.1067 & 2.16 & 7.3044 & 12.296 & 18.03 \\
\hline 0.1067 & 0.1067 & 0.1067 & 0.1067 & 0.1067 & 2.16 & 7.3044 & 12.296 & 18.03 \\
\hline 0.1067 & 0.1067 & 0.1067 & 0.1067 & 0.1067 & 2.16 & 7.3044 & 12.296 & 18.03 \\
\hline 0.1067 & 0.1067 & 0.1067 & 0.1067 & 0.1067 & 2.16 & 7.3044 & 12.296 & 18.03 \\
\hline 0.1067 & 0.1067 & 0.1067 & 0.1067 & 2.16 & 2.16 & 7.3044 & 15.75 & 18.03 \\
\hline 0.1067 & 0.1067 & 0.1067 & 0.1067 & 2.16 & 2.16 & 7.3044 & 15.75 & 18.03 \\
\hline 0.1067 & 0.1067 & 0.1067 & 0.1067 & 2.16 & 2.16 & 7.3044 & 15.75 & 18.03 \\
\hline 0.1067 & 0.1067 & 0.1067 & 0.1067 & 2.16 & 2.16 & 7.3044 & 15.75 & 18.03 \\
\hline 0.1067 & 0.1067 & 0.1067 & 0.1067 & 2.16 & 2.16 & 7.3044 & 15.75 & 34.31 \\
\hline 0.1067 & 0.1067 & 0.1067 & 0.1067 & 2.16 & 2.16 & 7.3044 & 15.75 & 34.31 \\
\hline 0.1067 & 0.1067 & 0.1067 & 0.1067 & 2.16 & 2.16 & 7.3044 & 15.75 & 34.31 \\
\hline 0.1067 & 0.1067 & 0.1067 & 0.1067 & 2.16 & 2.16 & 7.3044 & 15.75 & 34.31 \\
\hline 0.1067 & 0.1067 & 0.1067 & 0.1067 & 2.16 & 2.16 & 7.3044 & 15.75 & 34.31 \\
\hline 0.1067 & 0.1067 & 0.1067 & 0.1067 & 2.16 & 2.16 & 12.296 & 15.75 & 34.31 \\
\hline 0.1067 & 0.1067 & 0.1067 & 0.1067 & 2.16 & 2.16 & 12.296 & 15.75 & 34.31 \\
\hline 0.1067 & 0.1067 & 0.1067 & 0.1067 & 2.16 & 2.16 & 12.296 & 15.75 & 34.31 \\
\hline 0.1067 & 0.1067 & 0.1067 & 0.1067 & 2.16 & 2.16 & 12.296 & 15.75 & 34.31 \\
\hline 0.1067 & 0.1067 & 0.1067 & 0.1067 & 2.16 & 7.3 & 12.296 & 15.75 & 34.31 \\
\hline 0.1067 & 0.1067 & 0.1067 & 0.1067 & 2.16 & 7.3 & 12.296 & 15.75 & 34.31 \\
\hline
\end{tabular}


Table 4: Simulation Calculation Goodness Distribution

\begin{tabular}{|c|c|c|c|c|c|}
\hline nj-number observed & probability & Expected value & $($ nj-npj)^2/npj & & \\
\hline 133 & 0.82 & 142 & 0.577960643 & & \\
\hline 34 & 0.15 & 26 & 2.407801825 & & \\
\hline 7 & 0.03 & 6 & 0.220683623 & & \\
\hline 174 & 1.00 & chisq calculate 3.206446091 &
\end{tabular}

Hipotesis Ho - distribution follow exponent

H1- distribution not follow exponent

\begin{tabular}{|c|c|}
\hline dof $=3-1-1$ & 2.00 \\
\hline alfa & 0.05 \\
\hline chisq frm table & 3.84 \\
\hline
\end{tabular}

\begin{tabular}{|c|c|}
\hline lambda (MLE) & mttf \\
\hline 0.18835939 & 5.309 \\
\hline
\end{tabular}

result accept Ho because chisq calculate less than chisq frm table

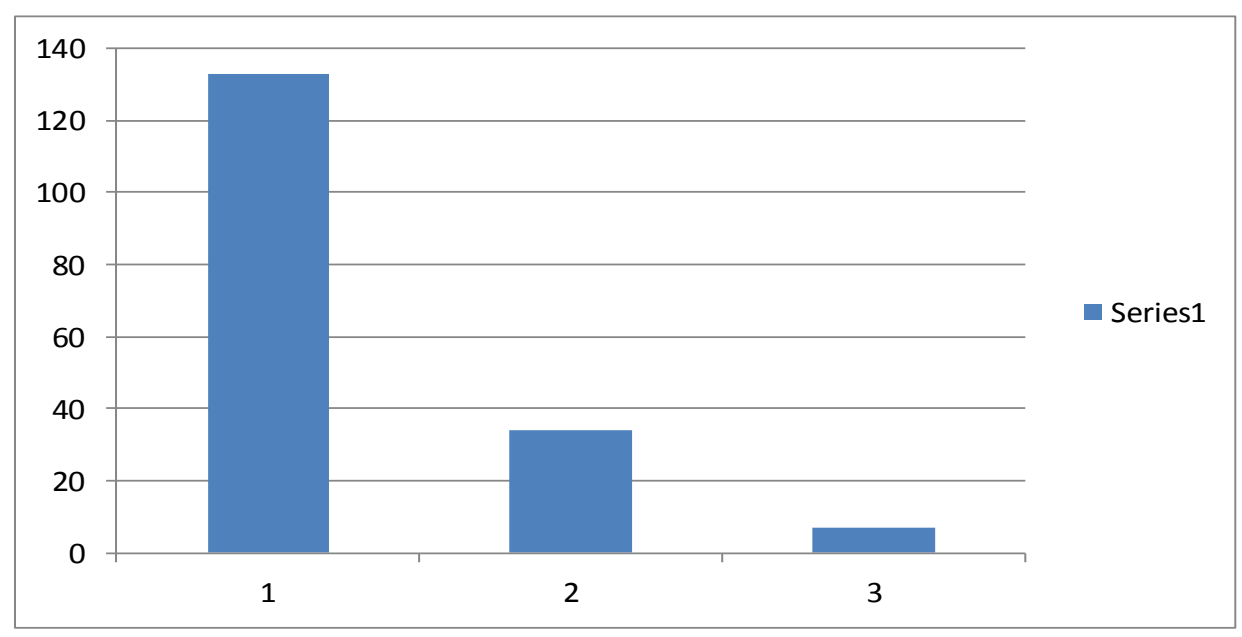

Figure 2: Histogram of the Distribution Failure Data

\section{DISCUSSION}

Table 5: Result show Failure Distribution model

\begin{tabular}{|c|c|c|c|c|c|}
\hline Delay Time & \multicolumn{2}{|c|}{ Parameter } & \multicolumn{2}{|c|}{ Goodness of fit } & \multirow{2}{*}{$\begin{array}{c}\text { Degree } \\
\text { of } \\
\text { Freedom }\end{array}$} \\
\hline & $\alpha$ & $\hat{\beta}$ & $\chi^{2}$ & $\chi_{n=0.05}^{2}$ & \\
\hline Exponential & - & 5.309 & 3.20645 & 3.841 & 4 \\
\hline Gamma & 13.7277 & 0.3868 & 742.543 & 3.84 & 3 \\
\hline Weibull & 2.8535 & 0.4885 & 54.3362 & 5.991 & 3 \\
\hline Normal & 5.7135 & 8.6064 & 44.5165 & 5.991 & 3 \\
\hline
\end{tabular}

In presented in Table 5 the value of high for MLE (Lambda) is $\hat{\alpha}$ and $\hat{\beta}$ all the distribution which strongly indicates that none of the distribution could be accepted as the representative distribution of the failure data given the existing data. Information criteria were also calculated aims to provide further evidence on which distribution should be selected. The purpose of parameter and Goodness of fit are to suggest which distribution has to be chosen when the test is accepted and possibly a tied among them. The selection of distribution is according to the lowest value of $\chi^{2}$ and $\chi_{n}^{2}$. These results prove that the distribution parameter for hostel building management in Malaysia. Distributions. The index of fit chisq from table 1.6 less 3.84 than the chisq calculated is 3.206446091, mean that selecting pattern best fit failure distribution follows the exponential distribution failure rate data hostel building component to compare other distribution of weibull, normal and gamma distribution test present the values of parameter 2.8535,04885 ,5.7135, 8.6064 and $13.7277,03868$, respectively. The goodness of fit , of weibull distribution shows higher value of $\chi^{2}=54.332$ and $\chi_{n}^{2}=5.991$, of normal distribution shows higher value of $\chi^{2}=44.5165$ and $\chi_{n}^{2}=5.99$, and of gamma distribution 
shows higher value of $\chi^{2}=742,543$ and $\chi_{n}^{2}=3.842$ .Therefore, traditional approach concludes that the best fit failure distribution follows the exponential distribution. In the new approach result, the shape $\mathrm{p}$, for exponential test is determined and the value of $\chi^{2}=3.206$ and $\chi_{n}^{2}=3.841$

This result indicates that the best fit of the failure time (table 1.5) also follows the exponential distribution (refer to estimation of shape parameters. This result proved that the approach proposed for failure distribution is exponent can be used as a practical technique in determining the best fit failure distribution in Hostel building maintenance in Malaysia University

\section{SUMMARY}

In this paper, a new approach to determine the best fit distribution is proposed. The basic idea in the approach is determine the shape parameters, exponential distribution test. From the shape parameters, $p$, the best fit distribution of failure time can be predicted [9-12]. Numerical example showed a similar result for both of traditional approach and the new approach. Simpler calculation steps to determine the best fit distribution is the main advantages by using a MLE and Goodness of a Distribution Fit approach compared to approach that used require more calculation steps. This new approach can assist engineers to reduce the time analysis and the result is valid for maintenance strategies purposes [11-13]. As a part of the future research, to show the indicator pattern of parameter for Malaysia University hostel building component maintenance apply other techniques to compare distribution fit failure .

\section{ACKNOWGEMENTS}

This research is supported by Kolej Universiti Islam Melaka (KUIM) include overall sponsored. This research is part of Degree of Doctor of Philosophy (PhD) in the Faculty Information and Communication Technology, Universiti Teknikal Malaysia Melaka (UTeM).

\section{REFERENCES}

[1] Y. Ab Wahab and A.S.H. Basari, "Building maintenance management preliminary finding of a case study in ICYM," Middle-East Journal of Scientific Research, vol. 17, no. 9, pp. 1260-1268, 2013.

[2] Y. Ab Wahab and A.S.H. Basari, "Analysis of down time and reliability estimation in hostel building maintenancea case study," Middle-East Journal of Scientific Research, vol. 17, no. 9, pp. 1260-1268, 2013.

[3] Yuseni Ab Wahab, Abd Samad Hasan Basari and Burairah Hussin 'Replacement Model for Hostel Building Case Study: ICYM," Middle-East Journal of
Scientific Research 21 (11): 1977-1981, 2014 ISSN 1990-9233

[4] Yuseni Ab Wahab, Abd Samad Hasan Basari and Burairah Hussin 'Replacement Model for Higher Education Institution Hostel Building Maintenance in Malaysia," International Journal of Trade, Economics and Finance, Vol. 5, No. 5, October 2014

[5] Yuseni Ab Wahab, Abd Samad Hasan Basari and Burairah Hussin" Building Maintenance Management Preliminary Finding of A Case Study in KUIM," National Conference Case Study , Universiti Utara Malaysia,June 2013.

[6] A. K.S. Jardine and A.H.C. Tsang, "Maintenance, replacement and reliability," 2006 CRC Press Mechanical Engineering, A Series of Textbooks and Reference Book, pp. 57- 97, 2006.

[7] R. P. Nicola and R. Dekker, "Optimal maintenance of multi-component systems: A review," in Murthy DNP, Kobbacy AKS, Ed. Complex system maintenance handbook, Amsterdam: Springer ch. 7, 2008

[8] Rosmaini Ahmad, Shahrul Kamaruddin, Mohzani Mokthar and Indra Putra Almanar, 'Identifying the Best Fit Failure Distribution and the Parameters of Machine's Component: A New Approach" Proceedings of International Conference on Man-Machine Systems 2006 September 15-16 2006, Langkawi, Malaysia

[9] Shaomin and Derek Clemente Croome "Reliability in whole life cycle of building system" Engineering Contruction and architecture management . vol. 136-153. No 2,2006 @ Emerald Group Publishing limited

[10] A. A. L. Olanrewaju, "Case for Quantitative analysis of defects in university building: User perspective," Journal Build Environment Project and Asset Management, vol. 2, no. 2. pp. $167-181,2012$

[11] Maillart, L.M and Pollock, S.M. 1999. The effect of failure-distribution specification errors on maintenance cost, Proceedings Annual Reliability and Maintainability Symposium

[12] Maillart, L.M and Pollock, S.M. 1999. The effect of failure-distribution specification errors on maintenance cost, Proceedings Annual Reliability and Maintainability Symposium

[13] Ebeling, C.E. 1997. Reliability and Maintainability Engineering, The McRaw-Hill Companies, INC, USA.

[14] Jardine, A.K.S. 1973. Maintenance Replacement and Reliability, Pitman Publishing, Bath. [3] Johnson, L.G. 1964. Theory and Technique of Variation Research, Elsevier, Amsterdam 